SHORT REPORT

\title{
Contextual effect on mortality of neighbourhood level education explained by earlier life deprivation
}

\author{
Øyvind Næss, Alastair H Leyland, George Davey Smith, Bjorgulf Claussen
}

J Epidemiol Community Health 2005;59:1058-1059. doi: 10.1136/jech.2005.036822

$\mathrm{V}$ arious aspects of socioeconomic conditions in the neighbourhood have in recent years been found to have an influence on morbidity and mortality even after individual characteristics are taken into account. ${ }^{1}$ Increasing evidence suggests that to measure fully the impact social conditions may have on mortality risk, the whole life course must be taken into account as mortality risk increases cumulatively over the life course. ${ }^{2}$ Few studies have combined ecological and life course factors to see if contextual effects may be explained by social conditions earlier in life at the individual level. ${ }^{34}$ Most studies of neighbourhood effects have had a cross sectional design or with short follow up. Effects seen could be a consequence of the fact that people in these areas may have different earlier life experiences that have not been fully taken into account. In this study we examine whether the contextual effect of educational level aggregated to the neighbourhood on mortality risk could be explained by earlier life deprivation.

\section{METHODS AND RESULTS}

A cohort of all inhabitants in Oslo aged 30-69 years in 1990 was linked to the censuses in 1960 to 1990, the Educational Register in 1990, and the Death Register 1990 to 1998. There were 131985 people $30-49$ years (29\% excluded) and 87533
50-69 years ( $20 \%$ excluded). Education was defined as primary education (7-9 years), middle school (10-11 years), secondary school (12 years), college (12-16 years), and university (over 16 years). Altogether 473 neigbhourhoods were registered at the census in 1990 to administer elections. Centile distribution (at neighbourhood level) of number of inhabitants per neighbourhood ranged from 8 (lower 5\%), 248 (median) to 968 (95\%). The age adjusted mortality rate (per 10000 ) did not vary by neighbourhood size. The proportion in each area in the age range 30-69 years with only primary education was used as the indicator of educational level in neighbourhoods. Housing conditions from the censuses in 1960, 1970, and 1980 provided information on earlier life deprivation at the individual level. Six aspects of housing conditions were included: rooms per household capita $(0,1,2)$, type of dwelling $(0,1,2)$, ownership $(0,1)$, toilet $(0,1)$, bath $(0,1)$, and telephone in dwelling $(0,1)$. This was summed for each individual and categorised into five roughly similar size groups. A logistic multilevel analysis was conducted to estimate neighbourhood variance in mortality adjusting for age only (model 1) and subsequently adding neighbourhood level education (model 2), individual level education (model 3), and earlier life deprivation (models 4 to 6). A full description of these variables in the same population is provided elsewhere. ${ }^{2}$

Table 1 Fixed effect ( $\beta$ and SE) of neighbourhood level education in 1990 (model 2) and variance (SE) on all causes of death by age and corresponding individualł level education (model 3) and by all individual level life course deprivation from 1960, 1970, and 1980 (model 5) in men and women who were residents in Oslo 1 January1990 aged 30-69

$\begin{array}{ll}\text { Model } 1 & \text { Model } 2 \\ \text { Age only } & \text { M1 + neighbourhood }\end{array}$

Model 3

Model 4

$\frac{\text { Model } 5}{M 4+1970} \frac{\text { Model } 6}{M 5+1980}$

\begin{tabular}{|c|c|c|c|c|c|c|}
\hline \multicolumn{7}{|l|}{ Age $30-49$} \\
\hline Individual level & - & - & $0.340(0.022)^{* * *}$ & $0.326(0.023)^{* * *}$ & $0.328(0.023)^{* * *}$ & $0.322(0.023)^{* * *}$ \\
\hline Neighbourhood & - & $2.633(0.357)^{\star * *}$ & $0.892(0.362)^{*}$ & $0.762(0.365)^{*}$ & $0.774(0.366)^{*}$ & $0.673(0.367)$ \\
\hline Variance (SE) & $0.206(0.037)^{\star * *}$ & $0.135(0.031)^{* * *}$ & $0.109(0.029)^{* * *}$ & $0.107(0.029)^{\star \star *}$ & $0.108(0.029)^{* * *}$ & $0.103(0.028)^{* * *}$ \\
\hline \multicolumn{7}{|c|}{ Women $(n=47172)$} \\
\hline \multicolumn{7}{|c|}{ Fixed effect income, $\beta$ (SE): } \\
\hline Individual level & - & - & $0.214(0.031)^{* * *}$ & $0.196(0.032)^{* * *}$ & $0.196(0.032)^{* * *}$ & $0.168(0.032)^{\star * *}$ \\
\hline Neighbourhood & - & $1.279(0.378)^{* * *}$ & $0.255(0.404)$ & $0.122(0.408)$ & $0.005(0.410)$ & $-0.296(0.412)$ \\
\hline Variance (SE) & $0.055(0.034)$ & $0.043(0.032)$ & $0.047(0.033)$ & $0.046(0.033)$ & $0.046(0.033)$ & $0.042(0.032)$ \\
\hline \multicolumn{7}{|l|}{ Age $50-69$} \\
\hline \multicolumn{7}{|c|}{ Men $(n=31353)$} \\
\hline \multicolumn{7}{|c|}{ Fixed effect income, $\beta$ (SE): } \\
\hline Individual level & - & - & $0.186(0.012)^{* * *}$ & $0.170(0.013)^{* * *}$ & $0.153(0.013)^{* * *}$ & $0.145(0.013)^{* * *}$ \\
\hline Neighbourhood & - & $1.682(0.016)^{* * *}$ & $0.654(0.202)^{* *}$ & $0.485(0.192)^{*}$ & $0.344(0.192)$ & $0.171(0.191)$ \\
\hline Variance (SE) & $0.103(0.015)^{* * *}$ & $0.073(0.012)^{* * *}$ & $0.042(0.009)^{* * *}$ & $0.036(0.009)^{\star * \star}$ & $0.026(0.008)^{* * *}$ & $0.022(0.007)^{* *}$ \\
\hline \multicolumn{7}{|c|}{ Women $(n=39039)$} \\
\hline \multicolumn{7}{|c|}{ Fixed effect education, $\beta$ (SE): } \\
\hline Individual level & - & - & $0.196(0.017)^{* * *}$ & $0.171(0.018)^{\star \star *}$ & $0.160(0.018)^{\star * *}$ & $0.154(0.018)^{\star \star *}$ \\
\hline Neighbourhood & - & $1.077(0.195)^{* * *}$ & $0.263(0.195)$ & $0.007(0.191)$ & $-0.095(0.189)$ & $-0.274(0.188)$ \\
\hline Variance (SE) & $0.048(0.011)^{\star * *}$ & $0.032(0.009)^{* * *}$ & $0.019(0.008)^{* *}$ & 0.011 (0.007) & $0.007(0.006)$ & $0.004(0.006)$ \\
\hline
\end{tabular}

${ }^{*} \mathrm{p}$ Value $<0.05,{ }^{* *} \mathrm{p}$ value $<0.01,{ }^{* * *} \mathrm{p}$ value $<0.001$. †Proportion in each neighbourhood with primary education only, lowest quartile of neighbourhoods ranging from 0 to 0.32 and highest from 0.36 to 0.44 . $\ddagger$ Primary education ( $7-9$ years), middle school ( $10-11$ years), secondary school ( 12 years), college ( $12-$ 16 years), and university (over 16 years). 


\section{What this study adds}

We have shown that earlier life social conditions at the individual level can be an important residual confounder when investigating the effect of neighbourhood on mortality risk. A significant effect of neighbourhood educational level became insignificant after adjustment for individual deprivation throughout the life course.

Multilevel analysis typically provides information on higher level variation (neighbourhood), some of which can be explained by the fixed effect of individual and neighbourhood level factors. Table 1 shows fixed effects of education at individual and neighbourhood level and variances in mortality risk across neighbourhoods in the two age groups. The variances were larger for men than for women and in the younger than the older age group. Adding neighbourhood level education reduced the variance substantially in both sexes and age groups. The effect of neighbourhood education was significant and stronger for men and the younger age group. Individual level education was then added. This reduced the neighbourhood level effect of education. Adding life course indicators of deprivation further attenuated the neighbourhood level effect in both sexes and age groups in a stepwise manner. Including life course deprivation seemed not to reduce the individual level effect of education substantially.

\section{COMMENTS}

We have shown that earlier life social conditions at the individual level can be an important residual confounder when investigating the effect of neighbourhood on mortality risk shortly before death. The accumulated life course effect of social deprivation at the individual level could explain an apparent contextual effect of education near time of death. A significant effect of neighbourhood educational level became insignificant after adjustment for individual deprivation throughout the life course. Adding life course indicators from the censuses in 1960, 1970, and 1980 reduced the neighbourhood effect in a stepwise manner. We know from other sources that indicators of social living conditions and mortality rates are distributed unevenly between small areas and administrative boroughs in the city. ${ }^{5}$ Life expectancy between these boroughs has been shown to differ by 15 years.

Those excluded had slightly higher age adjusted mortality (20 per 10000 person years compared with 17 among those included in the younger group). Similar figures in the older group were 89 and 72 . This could lead to underestimation of the neighbourhood effect if the excluded were socially disadvantaged. A large proportion of those excluded, particularly in the younger age group (94\%), were foreign born immigrants who did not live in Norway at the time of the 1960 census but were inhabitants in Oslo in 1990. The consistent effect seen in both age groups and sexes and the small proportion excluded suggest this has not affected the results substantially. To check alternative index constructions of housing deprivation, we reanalysed omitting telephone. This gave similar results.

Our main motivation for carrying out this study was to see if earlier life social conditions at the individual level could be an important residual confounder when investigating neighbourhood effects on mortality risk. We did not have social indicators from all across the life course for the older age

\section{Policy implications}

Policy makers tackling inequalities in health at the neighbourhood level should be cautious of evidence obtained from studies that fail to take the life course into account.

group, which means that social conditions in childhood could still be residually confounding our results. Inequality in mortality risk is thought to be accumulated across the life course, as has previously been shown in this population using the same life course indicators. ${ }^{2}$ This suggests that our choice of indicators is valid. But it could also be that other variables not measured along the life course could explain the contextual effect of education. Moreover, as we did not examine the contextual effects of education over time, we are not able to conclude whether such factors exert an influence. We would highlight the need for future research on ecological determinants of social inequality in mortality to take a life course approach. This will entail following up people's residential history to see if area effects can be found earlier in life.

\section{ACKNOWLEDGEMENTS}

We thank executive officer Britt Elin Bråten and Project Leader Finn Gjertsen, Statistics Norway, for linking data.

\section{CONTRIBUTORS}

ON and GDS designed the study. ON analysed and wrote the first draft and GDS and AL contributed to analysing and writing later versions of the paper. $\mathrm{BC}$ collected the data. ON will act as guarantor for the paper.

\section{Authors' affiliations}

$\varnothing$ Næess, National Institute of Public Health, Oslo, Norway

A H Leyland, MRC Social and Public Health Sciences Unit, University of Glasgow, UK

G Davey Smith, Department of Social Medicine, University of Bristol, UK B Claussen, Institute of General Practice and Community Medicine, University of Oslo, Norway

Funding: the work was funded by Health and Rehabilitation, Norway, the Medical Research Council and the Chief Scientist Office of the Scottish Executive and our own institutions.

Competing interests: none declared.

Ethical approval: ethical approval was not required for this study.

Correspondence to: $\operatorname{Dr} \varnothing$ Næss, Institute of General Practice and Community Medicine, PO Box 1130 Blindern, N-0317 Oslo, Norway; oyvind.nass@samfunnsmed.vio.no

Accepted for publication 19 July 2005

\section{REFERENCES}

1 Pickett KE, Pearl M. Multilevel analysis of neighbourhood socioeconomic context and health outcomes: a critical review. J Epidemiol Community Health 2001;55:111-22.

2 Naess O, Claussen B, Thelle D, et al. Cumulative deprivation and causespecific mortality. J Epidemiol Community Health 2004;58:599-603.

3 Ben Shlomo Y, Kuh D. A life course approach to chronic disease epidemiology: conceptual models, empirical challenges and interdisciplinary perspectives. Int J Epidemiol 2002;31:285-93.

4 Diez Roux AV. Estimating neighbourhood health effects: the challenges of causal inference in a complex world. Soc Sci Med 2004;58:1953-60.

5 Rognerud MA, Kruger Y, Gjertsen F, et al. Strong regional links between socio-economic background factors and disability and mortality in Oslo, Norway. Eur J Epidemiol 1998;14:457-63. 